\title{
Experimental Study and Kinetic Modeling of Laminar Flame Propagation in Premixed Stoichiometric n-butane-air Mixture
}

\author{
VENERA GIURCAN ${ }^{1}$, MARIA MITU1*, DOMNINA RAZUS ${ }^{1}$, DUMITRU OANCEA ${ }^{2}$ \\ ${ }^{1}$ Ilie Murgulescu Institute of Physical Chemistry, 202 Splaiul Independentei, 060021, Bucharest, Romania \\ 2 University of Bucharest, Department of Physical Chemistry, 4-12 Elisabeta Blvd., 030018, Bucharest, Romania
}

\begin{abstract}
The laminar burning velocities and propagation speeds of stoichiometric n-butane-air mixture were obtained for outwardly propagating spherical flames by measurements of pressure rise during the early stage of propagation in a spherical vessel. The experiments were carried out at various initial pressures within 0.3 and 1.2 bar, and various initial temperatures within 298 and $423 \mathrm{~K}$. The experimental laminar burning velocities were compared with those provided by the detailed kinetic modelling based on Warnatz mechanism for combustion of C1-C4 hydrocarbons, using INSFLA package. The baric and thermal coefficients of laminar burning velocities, calculated from their dependence on initial temperature and pressure, were compared with coefficients characteristic for other fuel-air mixtures. The overall activation parameters (reaction order and activation energy) are reported and discussed in comparison with similar data characteristic for alkaneair flames.
\end{abstract}

Keywords: laminar burning velocity; propagation speed; $n$-butane; deflagration; overall activation parameters

The laminar burning velocity and the propagation speed (or space velocity) are the most important properties of fuel-air flames, used for design of various combustors and of explosion suppression devices or for predicting the performance and emissions of internal combustion engines. Various aspects of combustion phenomena can be understood and predicted by means of the laminar flame speed: the turbulent flame structure and speed, the flame front instabilities, the flame extinction through heat loss and stretch and the flame stabilization. Knowledge of the burning velocity helps predicting the flame propagation during explosions in enclosures with a complex geometry by means of Computational Fluid Dynamics simulation programs. For these reasons, it has long been the subject of extensive experimental and theoretical investigation, over a wide range of operating conditions. At the same time, the propagation speed is interesting for evaluation of critical conditions for flash-back of flames in elongated vessels or pipes. Their investigation, performed on widely used fuel-air mixtures, afford a better control of the combustion process, both from the point of view of safety and its utilization as a source of energy.

The laminar burning velocity of a premixed flame $S$ is defined as the velocity of the flame with respect to the unburned gas behind the flame front, assumed to be at rest. It depends on fuel type, equivalence ratio of the flammable mixture and on its pressure and temperature. The laminar burning velocity is extensively examined, using both experimental and theoretical approaches, as it is directly influenced by the overall rate of fuel oxidation in the flame front; therefore, it is widely used for development and validation of chemical mechanisms describing the high temperature oxidation of hydrocarbons [1,2]. At the same time, the laminar burning velocity can be used for calculating the overall activation parameters of fuel oxidation under flame conditions (overall activation energy and overall reaction order), used as input data for Computational Fluid Dynamics (CFD) modelling of explosion propagation in various conditions [3,4]. The propagation speed $S_{S}$ is defined as the velocity of the flame front with respect to the vessel where combustion takes place, i.e. a fixed reference system. The propagation speed depends on the same parameters as the laminar burning velocity $[5,6]$ and, additionally, on the flow pattern. Both laminar burning velocity and the propagation speed can be determined by experimental techniques using stationary flames (flames anchored on a burner; stagnation flow flames) or nonstationary flames (flames propagating in a tube; outwardly propagating flames) $[2,5,6]$. Experiments based on flames propagating in closed vessels with central ignition are most adequate for measurements of burning velocity and propagation speed in wide ranges of pressure and temperature, far from ambient [7-9] .

$n$-Butane was chosen as test fuel in the present study, since it is commonly used as fuel in automotive engines and domestic heaters, either alone or in a mixture with propane (as Liquefied Petroleum Gas, known as LPG). nButane is used also as feedstock for the manufacture of ethylene and butadiene, a key ingredient of synthetic rubber. The mixtures of $n$-butane with air were studied in various conditions, by various techniques [10-23]. However, most data refer to flames at ambientinitial conditions, and only a few studies examine the influence of pressure and/ or temperature on the laminar burning velocity or on the propagation speed.

Early data on the laminar burning velocity for $n$-butaneair mixtures with various equivalence ratios at ambient initial conditions were reported by Gibbs and Calcote [10] and by Gunther and J anisch [11] from experiments with flames anchored on a Bunsen burner. Experiments with $n$ butane blended with hydrogen using a flat flame burner [12] revealed a great influence of hydrogen, even in small amounts, on the laminar burning velocity of $n$-butane-air mixtures. More recent measurements using the counterflow twin flames method (Davis et al. [13], Hirasawa et al. [14]) and the heat flux method (Bosschaart and de Goey [15], Dirrenberger et al. [16]) delivered stretch-corrected laminar burning velocities of $n$-butane-air with various equivalence ratios at ambient initial pressure. Their results were recently used to validate a reduced reaction mechanism developed by Prince et al. [17] for predicting not only the laminar flame propagation in $n$-butane-air

\footnotetext{
* email: maria_mitu@icf.ro, Phone: +40-21-3121147
} 
mixtures, but their self-ignition as well. Data on pressure influence on laminar burning velocities of $n$-butane-air were obtained by the constant volume bomb technique. Nair and Gupta [18] reported burning velocities of $n$-butaneair at initial pressures within 1-5bar from transient pressure measurements during explosions in a closed spherical vessel. Using the same technique, Clarke et al. [19] determined the dependency of the laminar burning velocity on pressure for the stoichiometric $n$-butane-air mixture under micro-gravity. Experiments with rich $n$-butane-air mixtures at elevated temperatures and pressures in a closed vessel were used by Frolov [20] to examine a detailed reaction mechanism of $n$-butane oxidation in premixed flames, able to describe both forced ignition and self-ignition processes. Extended data on flame propagation in $n$-butane-air mixtures with equivalence ratios within 0.8 and 1.4 , initial temperature within 320 and $470 \mathrm{~K}$ and initial pressure within 1 and 15 bar were reported by Marshall et al. [21] using pressure measurements during combustion in a spherical vessel. Using lean and rich $n$-butane-air mixtures, Kelley and Law [22] discussed the influence of flame stretch on laminar burning velocity determined by means of flame radius measurements on outwardly propagating spherical flames, an extremely useful correction meant to eliminate the strong influences of the ignition transient and chamber confinement during the initial and final periods of the flame propagation.

The present paper reports the laminar burning velocities and propagation velocities of the stoichiometric $n$-butaneair mixture determined by measurements of pressure rise during the early stage of outwardly propagating spherical flames, in experiments at various initial pressures $(0.3$ $1.2 \mathrm{bar})$ and temperatures $(298-423 \mathrm{~K})$. The laminar burning velocities of the stoichiometric $n$-butane-air mixture complete thus earlier published data on laminar burning velocities of propane-, $n$-butane- and LPG-air mixtures with variable equivalence ratios at ambient initial conditions [24]. The measured laminar burning velocities are compared with the computed burning velocities obtained by the detailed modelling of free laminar premixed flames using the kinetic mechanism developed by Warnatz [2]. Based on the dependence of the laminar burning velocities on initial temperature and pressure, their baric and thermal coefficients are calculated and compared with available literature data. The temperature and pressure dependencies of laminar burning velocities (i.e. of the overall reaction rate) deliver also the overall reaction order and the overall activation energy of $n$-butane oxidation in flame, after assuming the $n$-butane oxidation in flame follows a simple one-step kinetics, valid over restricted ranges of pressure and flame temperature variation.

\section{Experimental part}

Experiments were conducted in a set-up composed from a vacuum and gas-feed line, tight at pressures between $0.1 \mathrm{mbar}$ and 4 bar. The line connects the explosion vessel to the vacuum pump, the gas cylinders with fuel and air and the vessel for mixture storage. The vacuum pump maintains a vacuum of $0.1 \mathrm{mbar}$ in the explosion vessel, after each experiment. The fuel-air mixture was prepared in a $10 \mathrm{~L}$ cylinder at a total pressure of $4 \mathrm{bar}$ by partial pressure method and the mixture was used $48 \mathrm{~h}$ after. The initial pressures of the fuel-air mixture were measured by a strain gauge manometer (Edwards type EPS-10HM). Throughout the paper the pressure was expressed in bar absolute.
The explosion vessel was a stainless-steel sphere ( 10 $\mathrm{cm}$ inner diameter), equipped with two ionization probes (tips mounted 3 and $5 \mathrm{~mm}$ away from the side wall, respectively) used to monitor the position of the flame front. Ignition was made with inductive-capacitive sparks produced by a standard automotive ignition coil between two opposed, collinear stainless-steel electrodes; the spark gap of constant width $(3.0 \mathrm{~mm})$ was located in the geometrical centre of vessel. The explosion vessel could be electrically heated up to $170^{\circ} \mathrm{C}$. Its temperature was adjusted by $\pm 1^{\circ} \mathrm{C}$ using an AEM 1RT96 controller and monitored by a K-type thermocouple.

The pressure variation during explosions was recorded with a piezoelectric pressure transducer Kistler 601A mounted in a special adapter, maintained at $(25 \pm 0.5)^{\circ} \mathrm{C}$ by a water jacket. The pressure transducer was connected to a Charge Amplifier Kistler 5001SN. The signals from the ionization probe and from the Charge Amplifier were recorded with an acquisition data system TestLab ${ }^{T M}$ Tektronix 2505 , by means of an acquisition card type AA1, usually at 7000 signals/s. Other details regarding the experimental set-up and the operating mode were previously given [7, 9, 25-27].

Three tests were carried out for each pressure and temperature. Errors in experimental burning velocities were estimated within 2.5 and $3.5 \%$.

$n$-Butane (99.99\%) (SIAD Italy) was used without a further purification.

\section{Computing programs}

The adiabatic flame temperatures in isobaric combustion, assuming the thermodynamic equilibrium is reached within the flame were calculated using the ECHIMAD program developed by Geana et al [28]. The program is based on a general algorithm for computing the equilibrium composition of products for fuel-oxidizer gaseous mixtures by determining the minimum of the free enthalpy. Fifteen compounds ( $\mathrm{C}_{\text {oraphite, }} \mathrm{O}_{2}, \mathrm{~N}_{2}, \mathrm{H}_{2} \mathrm{O}, \mathrm{CO}, \mathrm{CO}_{2}$, $\mathrm{H}_{2}, \mathrm{NO}, \mathrm{CH}_{4}, \mathrm{C}_{2} \mathrm{H}_{2^{\prime}} \mathrm{C}_{3} \mathrm{H}_{8^{\prime}} \mathrm{C}_{4} \mathrm{H}_{10^{\prime}}, \mathrm{H}^{\prime}$, Ophite $\mathrm{H}$ and $\mathrm{O}$ ) ' were taken into account. The heat capacities (expressed as $C_{p}=f(T)$ polynomials), the standard enthalpies of formation at 298 $\mathrm{K}$ and the standard entropies at $298 \mathrm{~K}$ were taken from literature [29]. The calculations were made for various initial temperatures within 298-423 K. Other details were previously given [30].

The kinetic modelling of $n$-butane-air laminar adiabatic premixed flames in various conditions was made by means of INSFLA package. The runs were performed for the isobaric combustion at 1 bar initial pressure and various initial temperatures within $298 \mathrm{~K}$ and $423 \mathrm{~K}$. The modelling was made using the mechanism developed by Warnatz for combustion of C1-C4 hydrocarbons ( 53 chemical species, 592 elementary reactions) [2,31]. Updated values of several rate coefficients, for the rate-limiting reactions in $n$-butane-air oxidation were taken from Heghes [32].

\section{Results and discussions}

Experimental laminar burning velocities

A simple way to determine the laminar burning velocity of a fuel-air mixture is to restrict the examination of flame propagation to the early stage of an outwardly propagating flame, when the temperature gradients in both unburned and burned gas are small and can be neglected. This simple method is based on the relationship between the pressure increase in the early stage $\Delta p$ and the time from ignition, $t$ [33]: 


$$
\Delta p=k t^{3}=K p_{0} \frac{S_{u}^{3} t^{3}}{V_{0}}
$$

where $S_{u}$ is the laminar burning velocity, $k$ - the constant of cubic law, $V_{0}$ - the volume of explosion vessel and $K$ - a constant dependent on the flammable mixture composition.

The constant of the cubic law, $k$, was determined for each experimentbya nonlinear regression method of $\Delta p(t)$ data, assuming the validity of the relationship:

$$
\Delta p=\alpha+k \cdot(t-\beta)^{3}
$$

where $\alpha$ and $\beta$ are pressure and time corrections respectively, meant to eliminate the signal shift of pressure transducer and any possible delay in signal recording. The computation was restricted to a pressure range $p_{0} \leq p \leq 2 p_{0}$ for all experiments. The correction taken into account for the time delay $\beta$ eliminates the first period necessary for the formation of the flame kernel (the minimal flame radius) thus compensating the stretch effects [34].

At ambient initial temperature and pressure the laminar burning velocity of the stoichiometric n-butane-air was found $S_{0}=38.4 \mathrm{~cm} \mathrm{~s}^{-1}$, in very good agreement with stretch-corrected burning velocities reported in literature: $38.0 \mathrm{~cm} \mathrm{~s}^{-1}$, obtained with the heat flux method [13,14]; $37.1 \mathrm{~cm} \mathrm{~s}^{-1}$, obtained with the counterflow twin flame method [15] and $36.9 \mathrm{~cm} \mathrm{~s}^{-1}$ [18]. Earlier measurements using burner-stabilized stationary flames delivered noncorrected burning velocities, higher than the present measurements: $S_{u, 0}=44.8 \mathrm{~cm} \mathrm{~s}^{-1}$ for moist stoichiometric n-butane-air mixture (0.31 mole\% water in air) [10], 43.4 $\mathrm{cm} \mathrm{s}^{-1}$ [11], and $44.0 \mathrm{~cm} \mathrm{~s}^{-1}$ [12], for the stoichiometric $n$ butane-air mixture at ambient initial conditions. More recent results, obtained by measurements on the early stage of outwardly propagating flames, corrected for flame stretch and curvature, are much lower: $S_{u, 0}=34.5 \mathrm{~cm} \mathrm{~s}^{-1}$ $[21,22]$, and $35.0 \mathrm{~cm} \mathrm{~s}^{-1}$ [23].

The pressure increase determined the decrease of laminar burning velocity, at all initial temperatures, as shown in figure 1, where the best fitlines were also plotted.



Fig. 1. Initial pressure influence on laminar burning velocity, at various initial temperatures; experimental data, stoichiometric $n$ $\mathrm{C}_{4} \mathrm{H}_{10}$-air mixture
The data were analysed according to an empirical power law:

$$
S_{u}=S_{u, r e f}\left(\frac{p}{p_{\text {ref }}}\right)^{v}
$$

where $S_{u, r e f}$ is the laminar burning velocity at reference pressure $p$ ref and $v$ is the baric coefficient.

Choosing the ambient pressure as reference, $p_{\text {ref }}=1$ bar, the baric coefficients of laminar burning velocities for the stoichiometric $n$-butane-air mixture at various temperatures were calculated by a non-linear regression analysis of $S_{u}=f(p)$. The results are given in table 1 .

In the examined temperature range the baric coefficients of experimental laminar burning velocities seem to be constant, with deviations within 6-12\%. They are close to the baric coefficients of laminar burning velocities found for other stoichiometric alkane-air flames: $v=-0.17$ for ethane-air [9] and propane-air mixture [35] at ambient initial temperature. In measurements between 1 and 5 bar on stoichiometric $n$-butane-air mixture at $298 \mathrm{~K}$, Nair and Gupta found $v=-0.11$ [18].

Laminar burning velocities of $n$-butane-air corrected for stretch effects, reported by Marshall etal. [21] for pressures between 1 and 10 bar, and Wu et al. [23] for pressures between 1 and 7 bar, match well the present measurements, as shown in figure 2 .

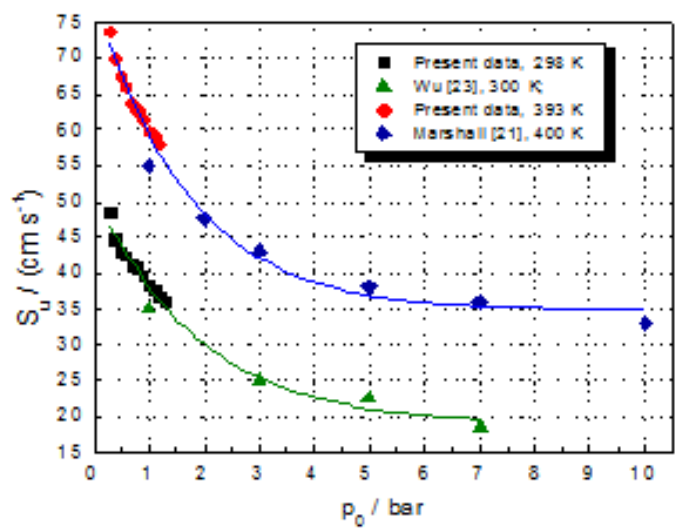

Fig. 2. Laminar burning velocities of stoichiometric $n$-butane-air, from measurements on outwardly propagating flames

According to recent studies on $\mathrm{H}_{2}$-air flames [36] the decrease of laminar burning velocity ${ }^{2}$ with the increase of initial pressure can be understood by the suppression of overall chemical reaction due to the decrease of $\mathrm{H}$ and $\mathrm{OH}$ mole fractions in flames. Indeed, strong correlations were found between the laminar burning velocity and the maximum radical concentrations of $\mathrm{H}$ and $\mathrm{OH}$ radicals in the reaction zone of premixed flames of $\mathrm{H}_{2}, \mathrm{CH}_{4}^{-}, \mathrm{C}_{2} \mathrm{H}_{3}$-air flames [2,36-38]; high laminar burning velocities correspond to high radical concentrations in the reaction zone.

At constant pressure, the temperature increase results in the increase of laminar burning velocities, as shown by data in Figure 3, where the best fit plots are also given. The data were analysed using the empirical power law:

$$
S_{u}=S_{u, r e f}\left(\frac{T}{T_{0}}\right)^{\mu}
$$

Table 1

THE BARIC COEFFICIENTS OF MEASURED LAMINAR BURNING VELOCITIES OF STOICHIOMETRIC $n-\mathrm{C}_{4} \mathrm{H}_{10}-$ AIR MIXTURES AT VARIOUS INITIAL TEMPERATURES

\begin{tabular}{|c|c|c|c|c|c|}
\hline$T_{0} / \mathrm{K}$ & 298 & 333 & 363 & 393 & 423 \\
\hline$-v$ & $0.171 \pm 0.014$ & $0.176 \pm 0.011$ & $0.165 \pm 0.010$ & $0.176 \pm 0.022$ & $0.157 \pm 0.012$ \\
\hline
\end{tabular}




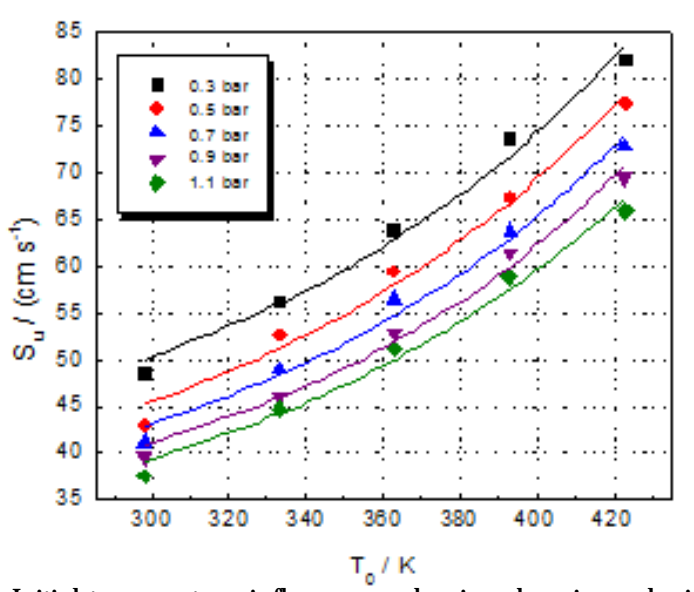

Fig. 3. Initial temperature influence on laminar burning velocity of stoichiometric $n$-butane-air mixture; experimental data

where $S_{u \text { ref }}$ is the laminar burning velocity at reference temperature $T_{\text {ref }}$ and $\mu$ is the thermal coefficient. The ambient temperature was chosen as reference, $T_{\text {ref }}=298$ $K$, and the thermal coefficients were calculated by $a$ nonlinear regression analysis of $S_{u}=f\left(T_{0}\right)$ at various initial pressures. The results are given in table 2 .

Table 2

THE THERMAL COEFFICIENTS OF LAMINAR BURNING VELOCITIES OF STOICHIOMETRIC $n-\mathrm{C}_{4} \mathrm{H}_{10}$-AIR MIXTURE

\begin{tabular}{|c|c|c|c|}
\hline$p_{0}$ (bar) & $\mu$ & $p_{0}$ (bar) & $\mu$ \\
\hline 0.3 & $1.52 \pm 0.04$ & 0.8 & $1.58 \pm 0.01$ \\
\hline 0.4 & $1.70 \pm 0.06$ & 0.9 & $1.63 \pm 0.06$ \\
\hline 0.5 & $1.65 \pm 0.04$ & 1.0 & $1.61 \pm 0.03$ \\
\hline 0.6 & $1.64 \pm 0.03$ & 1.1 & $1.62 \pm 0.02$ \\
\hline 0.7 & $1.63 \pm 0.02$ & 1.2 & $1.65 \pm 0.01$ \\
\hline
\end{tabular}

The thermal coefficients of laminar burning velocities range between 1.52 and 1.70, a domain characteristic to alkane-air mixtures. Literature data based on laminar burning velocities measured in closed vessel experiments at ambient initial pressure are quite close: $\mu=1.63$ [21] and $\mu=1.56$ [23]. In comparison, for the stoichiometric ethane-air mixture at various initial pressures the thermal coefficients range between 1.63 and 1.69 [8,9]; for the stoichiometric propane-air mixture at ambient initial pressure $\mu=1.63$ was reported [35].

\section{Computed laminar burning velocities}

The laminar burning velocities computed by means of INSFLA package, using the updated Warnat mechanism for C1-C4 hydrocarbons, are plotted in figure 4 together with the measured burning velocities from the present paper and with measured and calculated literature data [23]. For the calculated burning velocities, the best fit lines are shown as well.

The laminar burning velocities computed with INSFLA package are lower in comparison with the present measured data, but match well the laminar burning velocities reported by Wu et al. [23] for the temperature range between 300 and $395 \mathrm{~K}$. In contrast to this, the laminar burning velocities computed by Wu etal. [23] using the Aramco 1.3 mechanism [39] are closer to the present experimental data. The results reported by Hirasawa et al. [14] for the laminar burning velocity of $n$-butane-air at ambient initial conditions: $S=42 \mathrm{~cm} \mathrm{~s}^{-1}$ and $S=40$ $\mathrm{cm} \mathrm{s}^{-1}$ (CHEMKIN package, Dâvis mechanism [ 40$]$ ) match also our experimental results.

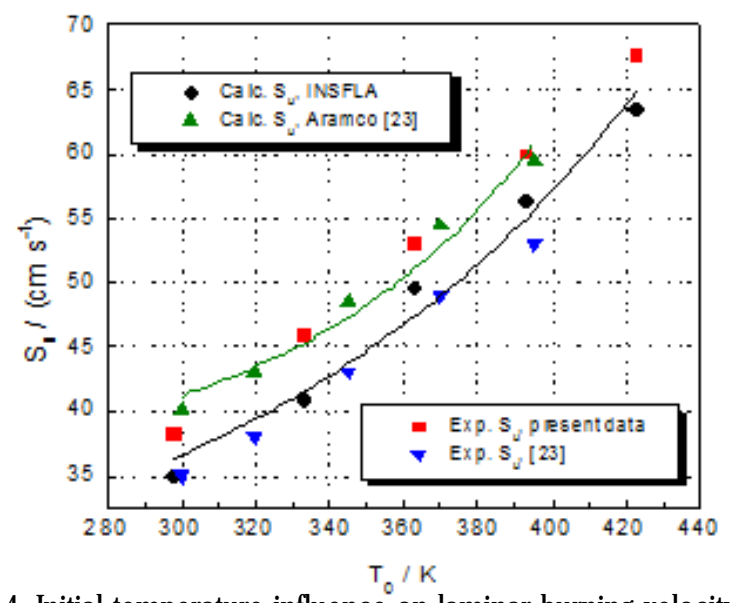

Fig. 4. Initial temperature influence on laminar burning velocity of stoichiometric $n$-butane-air mixture at $p_{0}=1$ bar; experimental, computed and literature data

\section{The propagation speeds}

The propagation speed $S_{\text {i }}$ is related to the laminar burning velocity $S_{u}$ by the relationship $[6,41]$ :

$$
S_{s}=E_{0} \cdot S_{u}
$$

where $E_{0}$ is the expansion coefficient of the unburnt gas in isobaric combustion, defined as the ratio of the unburnt and burnt gas densities:

$$
E_{0}=\frac{\rho_{u}}{\rho_{b}}=\left(\frac{T_{f, p}}{T_{0}}\right)\left(\frac{n_{e}}{n_{0}}\right)
$$

with $T_{f, p}$ - the adiabatic flame temperature of isobaric combustion at initial temperature $T_{0} ; n_{0}$ - the initial mole number; $n_{e}$ - the final (end) mole number, at flame temperature.

The propagation speeds $S_{s}$ of $n$-butane-air flames were determined from the laminar burning velocities $S_{u}$ and the expansion factors $E_{0}$ using equation (5). Relevant values of the adiabatic flame temperatures $\left(T_{f, p}\right)$ for $n$ - $\mathrm{C}_{4} \mathrm{H}_{10}$-air mixtures burning at constant pressure and various initial temperatures together with the corresponding expansion coefficients are given in table 3 .

\begin{tabular}{|c|c|c|}
\hline$T_{0} / \mathrm{K}$ & $T_{f_{0}} / \mathrm{K}$ & $E_{0}$ \\
\hline 298 & 2274 & 8.07 \\
\hline 333 & 2290 & 7.27 \\
\hline 363 & 2302 & 6.71 \\
\hline 393 & 2316 & 6.24 \\
\hline 423 & 2329 & 5.83 \\
\hline
\end{tabular}

Table 3

ADIABATIC FLAMES TEMPERATURESAND EXPANSION COEFFICIENTS, OF STOICHIOMETRIC $n$ BUTANE-AIR MIXTURE, AT $p_{0}$ = 1 bar AND VARIOUS INITIAL TEMPERATURES

A set of representative values of propagation speeds $S$ obtained from experimental laminar burning velocities of the stoichiometric $n$-butane-air mixture are given in figures 5 and 6 . The pressure increase determines the decrease of the propagation speed while the temperature increase determines the increase of the propagation speed.

At ambient initial temperature and pressure, the propagation speed of stoichiometric $n$-butane-air mixture, $S_{s}=310 \mathrm{~cm} \mathrm{~s}^{-1}$, is close to $S_{c}=328 \mathrm{~cm} \mathrm{~s}^{-1}$ of the stoichiometric $\mathrm{C}_{3} \mathrm{H}_{8}$-air mixture $\left.{ }^{4} 42\right]$, but higher when compared to the propagation speeds of the stoichiometric $\mathrm{CH}_{4}$-air mixture $\left(\mathrm{S}_{\varepsilon}=210 \mathrm{~cm} \mathrm{~s}^{-1}\right)$ [43] and stoichiometric $\mathrm{C}_{2} \mathrm{H}_{6}$-air mixture $\left(\xi_{s}=235 \mathrm{~cm} \mathrm{~s}^{-1}\right)$ [9].

Similar to the laminar burning velocity, the dependence of $S_{S}$ on pressure can be written as an empirical power law: 


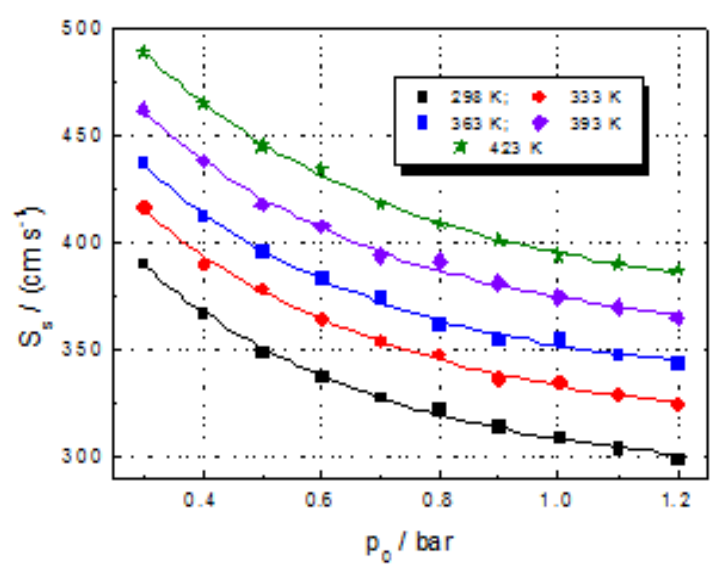

Fig. 5. Propagation speeds of stoichiometric $n$-butane-air mixture versus the initial pressure at various initial temperatures.

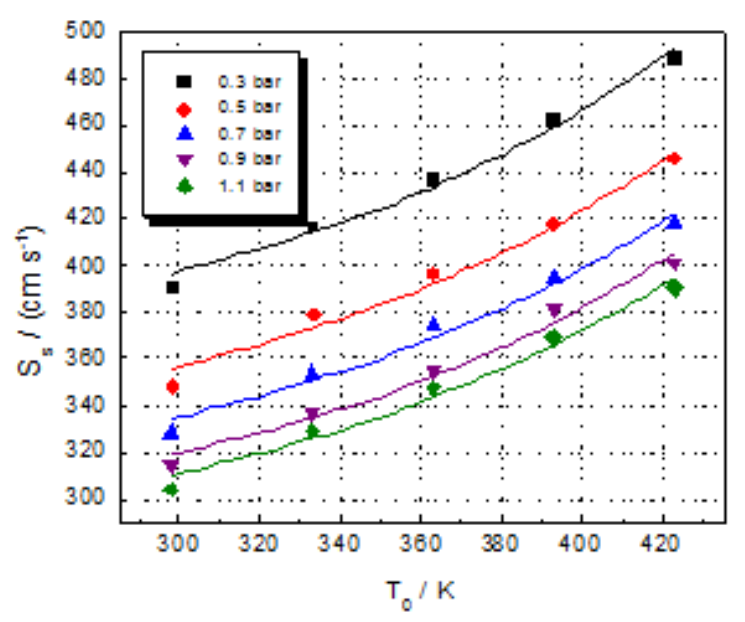

Fig. 6. Propagation speeds of stoichiometric $n$-butane-air mixture versus the initial temperature at various initial pressures

\begin{tabular}{|c|c|}
\hline$T_{0} / \mathrm{K}$ & $-v_{\mathrm{s}}$ \\
\hline 298 & $0.191 \pm 0.004$ \\
\hline 333 & $0.180 \pm 0.004$ \\
\hline 363 & $0.175 \pm 0.006$ \\
\hline 393 & $0.170 \pm 0.004$ \\
\hline 423 & $0.175 \pm 0.004$ \\
\hline
\end{tabular}

Table 4

THE BARIC COEFFICIENTS OF PROPAGATION SPEEDS OF STOICHIOMETRIC $n$ $\mathrm{C}_{4} \mathrm{H}_{10}$-AIR MIXTURE

$$
S_{s}=S_{s, r e f}\left(\frac{p}{p_{\text {ref }}}\right)^{v_{s}}
$$

where $S_{s, r e f}$ is the reference value of the propagation speed at $p=p$,ref The baric coefficients $v_{s}$, calculated by a nonlinear regression analysis of data, are given in table 4 . The baric coefficients of the propagation speeds do not depend significantly on the initial temperature.

The baric coefficient of propagation speeds for the stoichiometric $n$-butane-air mixture $\left(v_{s}=-0.19\right)$ at ambient initial temperature is close to the baric coefficient of laminar burning velocities: $v=-0.17$. This behaviour is determined by a weak dependence of expansion coefficients $E_{0}$ on initial pressure. The present value of $v$ for the stoichiometric $n$-butane-air mixture at $298 \mathrm{~K}$ is also close to $v_{s}=-0.16$ reported for the stoichiometric propaneair mixture [42].

At constant initial pressure and composition, the dependence of propagation speeds on temperature can be described by the empirical power law with the form:

$$
S_{s}=S_{s, r e f}\left(\frac{T}{T_{r e f}}\right)^{\mu_{s}}
$$

where $S_{s, r e f}$ is the reference value of the propagation speed at $T=T_{\text {ref }}^{s, r e f}$ and $\mu_{s}$ is the thermal coefficient, calculated by a non-linear regression analysis of data.

The thermal coefficients $\mu$ determined for various initial pressures from experimental data range between 0.64 and 0.72 , as shown by data from table 5 . A close value of the thermal coefficient at 1 bar, $\mu_{s}=0.82$, was obtained using the computed propagation velocities at 1 bar. Similar data, referring to propane-air gaseous mixtures, reach higher values between 1.28 and 1.45 [42]. The thermal coefficients $\mu_{s}$ of propagation speeds are lower than the thermal coefficients of laminar burning velocities $\mu$, which range usually between 1.6 and 2.2; this is a consequence of the simultaneous temperature influence on $S_{u}$ and $T_{f l}$ which determine the propagation speed.

\begin{tabular}{|c|c|}
\hline$p_{0}$ (bar) & $\mu_{s}$ \\
\hline 0.3 & $0.640 \pm 0.027$ \\
\hline 0.5 & $0.681 \pm 0.034$ \\
\hline 0.7 & $0.686 \pm 0.015$ \\
\hline 0.9 & $0.707 \pm 0.031$ \\
\hline 1.0 & $0.705 \pm 0.016$ \\
\hline 1.1 & $0.712 \pm 0.011$ \\
\hline
\end{tabular}

Table 5

THE THERMAL

COEFFICIENTS OF

PROPAGATION SPEEDS OF

STOICHIOMETRIC $n$ - $\mathrm{C}_{4} \mathrm{H}_{10}$-AIR MIXTURE

\section{Overall activation parameters of $n$-butane oxidation in flames}

The laminar burning velocity is directly influenced by the overall reaction rate in the flame front, as shown by the relationship developed by the thermal theory of flame propagation [44]:

$$
S_{u} \approx\left(\frac{\lambda}{\rho C_{p}} \cdot C_{0}^{1-n} \cdot \exp \left(-E_{a} / R \overline{T_{f}}\right)^{1 / 2}\right.
$$

where $\lambda$ is the thermal conductivity, $\rho$ - the density and $C_{p}$ - the specific heat of the unburned gas; $C$ is the initial fuel concentration, $\overline{T_{f}}$ is the average temperature of the flame front, $n$ and $E$ are the overall activation parameters (reaction order and activation energy) and $\mathrm{R}$ is the universal gas constant.

In accord to this, the correlations found between the laminar burning velocity and the initial pressure (at constant temperature) and with the flame temperature (at constant initial pressure) can be used to evaluate an overall reaction order and the overall activation energy of combustion, assumed to be a one-step chemical process [5].

The overall reaction orders, $n$, are obtained from the baric coefficients of burning velocities:

$$
n=2(v+1)
$$

Equation (10) is a simplified form of equation (9) equation assuming that the terms involving the pressure dependence of flame temperature $T_{f}$ and of thermal diffusivity $\lambda /\left(\rho C_{p}\right)$ have very small values and can be neglected [45].

The overall reaction orders of $n$-butane oxidation in flame are given in table 6 . Within the examined temperature range the overall reaction orders are quasi-constant and close to overall reaction orders reported for ethane-air [9] and propane-air [46]. 
Table 6

THE OVERALL REACTION ORDERS OF $n-\mathrm{C}_{4} \mathrm{H}_{10}$ OXIDATION WITH AIR; STOICHIOMETRIC MIXTURE

\begin{tabular}{|c|c|c|c|c|c|}
\hline$T_{0} / \mathrm{K}$ & 298 & 333 & 363 & 393 & 423 \\
\hline$n$ & 1.66 & 1.65 & 1.67 & 1.65 & 1.69 \\
\hline
\end{tabular}

From the laminar burning velocity variation against the average flame front temperature $T_{f}$, the overall activation energy $E_{a}$ was calculated as the slope of correlations plotted in figure 7:

$$
\ln S_{u}=\text { Const }-\frac{E_{a}}{2 R \overline{T_{f}}}
$$

where $\bar{T}_{f}$ is the average flame temperature, which can be approximated as [47]:

$$
\overline{T_{f}}=T_{0}+0.74\left(T_{f}-T_{0}\right)
$$

where $T_{0}$ is the initial temperature and $T_{f}$ is the adiabatic flame temperature of the isobaric combustion.

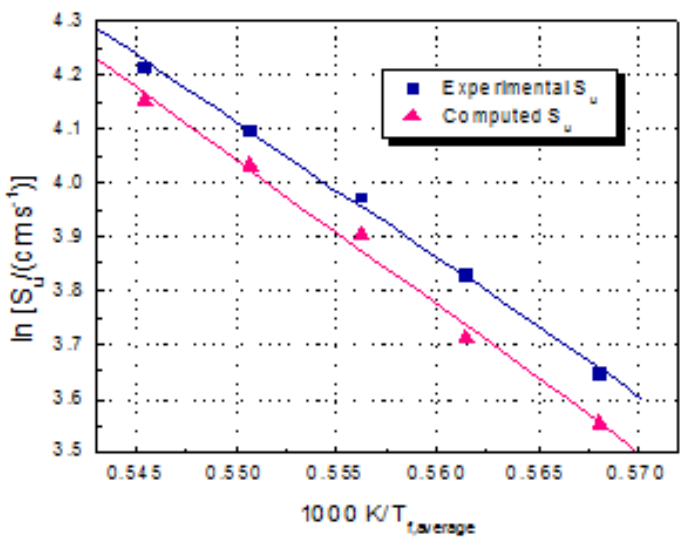

Fig. 7. Laminar burning velocity variation with the average flame temperature of stoichiometric $n$-butane-air mixture at ambient initial pressure

The activation energies obtained from the present data are: $E=416 \mathrm{~kJ} \mathrm{~mol}^{-1}$ (from measured laminar burning velocities) and $E_{2}=449 \mathrm{~kJ} \mathrm{~mol}^{-1}$ (from computed laminar burning velocities). They match closely the activation energy found for the stoichiometric ethane-air mixture at $p_{0}=1$ bar from measured laminar burning velocities: $E_{a}=$ $433 \mathrm{~kJ} \mathrm{~mol}{ }^{-1}$ [9]. Slightly lower activation energies wère reported for the stoichiometric propane-air mixture: $E=$ $365 \mathrm{~kJ} \mathrm{~mol}^{-1}$ [46] from similar data and for the stoichiometric ethylene-air mixture: $E_{2}=385 \mathrm{~kJ} \mathrm{~mol}^{-1}[48]$ based on examination of mass burning flux variation against the adiabatic flame temperature.

The flame propagation properties $[49,50]$ together with the ignition temperature [51-53] are important parameters to establish the safety regulation in gaseous flammable mixtures or for design of various combustors and of explosion suppression devices.

\section{Conclusions}

The laminar burning velocities and the propagation speeds of stoichiometric $n$-butane-air explosions in a spherical vessel with central ignition were obtained using mixtures at various initial pressures and various initial temperatures. The experiments were made including also data at much lower pressures as compared to other studies, completing thus the pool of available literature data for $n$-butane air laminar burning velocities.

The laminar burning velocities were calculated from pressure-time records in the early stage of spherical propagation. The propagation speeds were calculated using the laminar burning velocities and the expansion coefficients of unburned gas obtained from equilibrium calculation on $n$-butane-air flames. The experimental laminar burning velocities are compared with the computed burning velocities obtained from the numerical modelling of 1D laminar flames using the Warnatz mechanism for C1-C4 hydrocarbons, which delivers underestimated values in comparison with our results, but close to laminar burning velocities recently reported in literature.

Both laminar burning velocities and propagation speeds depend on initial pressure and temperature of the flammable mixture: they increase with the increase of the initial temperature but decrease with the increase of the initial pressure. Using these dependencies, their thermal and baric coefficients were calculated.

Even if the laminar burning velocities were obtained over a restricted range of initial pressures and temperatures, their thermal and baric coefficients have values within the usual range of variation, characteristic to hydrocarbon-air mixtures.

The overall activation parameters, reaction order and activation energy were also calculated and compared with other reported data. The overall reaction orders of the stoichiometric $n-C_{4} H_{10}$ oxidation by air are slightly influenced by the increase of the initial temperature. The value of activation energy obtained from the present measurements ranges well within the activation energies reported for other fuels.

Acknowledgement: The authors gratefully thank Prof. U. Maas (Heidelberg University, Germany) and Dr. D. Markus (PhysikalischTechnische Bundesanstalt, Braunschweig, Germany) for the permission to run the program INSFLA and for the provided assistance. The present study was partially financed by the Romanian Academy under research project Dynamics of fastoxidation and decomposition reactions in homogeneous systems of Ilie Murgulescu Institute of Physical Chemistry.

\section{References}

1. KONNOV, A. A., Proc. $7^{\text {th }}$ European Comb. Meeting, 2015, Budapest, Hungary.

2. WARNATZ, J., MAAS, U., DIBBLE, R., Combustion, $3^{\text {rd }}$ Edition, Springer Verlag, Berlin, Heidelberg and New York, 2001.

3. ANDERSEN, J., RASMUSSEN, C. L., GISLSSON, T., GLARBORG, P., Energy Fuels, 23, 2009, p. 1379.

4. VAN DEN BERG, A. C., J. Loss Prev. Process Ind., 22, 2009, p. 271. 5. LEWIS, B., VON ELBE, G., Combustion, Flames and Explosion of gases, $3^{\text {rd }}$ Ed., Acad. Press, New York and London, 1987, Chap. 5.

6.*** Handbook of explosion prevention and protection, HATTWIG, M., STEEN, H., Eds.; Wiley VCH Verlag, Weinheim, 2004, Chap. 3.

7. RAZUS, D., BRINZEA, V., MITU, M., MOVILEANU, C., OANCEA, D., Energy Fuels, 26, 2012, p. 901.

8. MITU, M., RAZUS, D., GIURCAN, V., OANCEA, D., Energy Fuels, 28, 2014, p. 2179.

9. MITU, M., RAZUS, D., GIURCAN, V., OANCEA, D., Fuel, 147, 2015, p. 27.

10. GIBBS, G. J., CALCOTE, H. F., J. Chem. Eng. Data, 4, no.3, 1959, p. 226.

11. GUNTHER, R., JANISCH, G., Chemie-Ing.Tech., 43, no. 17, 1971, p. 975.

12. SHER, E., OZDOR, N., Combust. Flame, 89, 1992, p. 214.

13. DAVIS, S. G., LAW, C. K., Combust. Sci. Technol., 140, 1998, p. 427.

14. HIRASAWA, T., SUNG, C. .., JOSHI, A., YANG, Z., WANG, H., LAW, C. K, Proc. Combust. Inst., 29, 2002, p. 1427.

15. BOSSCHAART, K. J., DE GOEY, L. P. H., BURGERS, J. M., Combust. Flame, 136, 2004, p. 261. 
16. DIRRENBERGER, P., LE GALL, H., BOUNACEUR, R., HERBINET, O., GLAUDE, P. A., KONNOV, A., BATTIN-LECLERC, F., Energy Fuels, 25, no. 9, 2011, p. 3875.

17. PRINCE, J. C., TREVINO, C., WILLIAMS, F. A., Combust. Flame, 175, 2017, p. 27.

18. NAIR, M. R. S., GUPTA, M. C., Combust. Flame, 22, 1974, p. 219. 19. CLARKE, A., STONE, R., BECKWITH, P., J. Inst. Energy, 74, no. 500,2001, p. 70.

20. FROLOV, S. M., BASEVICH, V. Y., SMETANYUK, V. A., BELYAEV, A. A., PASMAN, H. J., J. Loss Prev. Process Ind., 20, no. 4-6, 2017, p. 562. 21. MARSHALL, S. P., STONE, R., HEGHES, C., DAVIES, T. J., CRACKNELL, R. F., Combust. Theory Modelling, 14, no. 4, 2010, p. 519.

22. KELLEY, A. P., LAW, C. K., Combust. Flame, 156, no. 9, 2009, p. 1844.

23. WU, H., HU, E., YU, H., LI, Q., ZHANG, Z., CHEN, Y., HUANG, Z., Energy Fuels, 28, no. 5, 2014, p. 3412.

24. RAZUS, D., OANCEA, D., BRINZEA, V., MITU, M., MUNTEANU, V., Proc. $3^{\text {th }}$ European Comb. Meeting, Chania, Grecia, 2007, Paper VI-9. 25. GIURCAN, V., RAZUS, D., MITU, M., OANCEA, D., J. Loss Prev. Process Ind., 34, 2015, p. 65.

26. MITU, M., GIURCAN, V., RAZUS, D., OANCEA, D., Energy Fuels, 26, no. 8, 2012, p. 4840.

27. GIURCAN, V., MITU, M., RAZUS, D., OANCEA, D., Proc. Saf. Environm. Prot., 111, 2017, p. 94.

28. GEANA, D., POPESCU, D., MIHAl, M., ADOMNICA, L., Rev. Chim. (Bucharest), 36, 1985, p. 708.

29. KNAKE, O., KUBASCHEWSKI, O., HESSELMAN, K., Thermochemical properties of inorganic substances, $2^{\text {nd }}$ Ed., Springer Verlag, Berlin, Heidelberg and New York, 1991.

30. RAZUS, D., MITU, M., BRINZEA, V., OANCEA, D., Rev. Chim. (Bucharest), 58, 2007, p. 1170.

31. WARNATZ, J., Symp. (Intern.) on Comb., The Combustion Inst., 18, no. 1, 1981, p. 369.

32. HEGHES, C., C1-C4 Hydrocarbon oxidation mechanism, Ph.D. Thesis, Heidelberg University, 2006.

33. RAZUS, D., OANCEA, D., MOVILEANU, C., J. Loss Prev. Process Ind., 19, no. 4, 2006, p. 334.
34. PRODAN, M., MITU, M., RAZUS, D., OANCEA, D., Rev. Roumaine Chim., 61, 2016, p. 299.

35. RAZUS, D., BRINZEA, V., MITU, M., OANCEA, D., Energy Convers. Manage., 51, no. 12, 2010, p. 2979.

36. HU, E., HUANG, Z., HE, J., MIAO, H., Intern J. Hydrogen Energy., 34, no. 20, 2009, p. 8741.

37. ROZENCHAN, G., ZHU, D. L., LAW, C. K., TSE, S. D., Proc. Combust. Inst., 29, no. 2, 2002, p. 1461.

38. MOVILEANU, C., RAZUS, D., OANCEA, D., Energy Fuels, 25, no. 6, 2011, p. 2444.

39. METCALFE, W. K., BURKE, S. M., AHMED, S. S., CURRAN, H. J., Int. J. Chem. Kinet., 45, no. 10, 2013, p. 638.

40. DAVIS, S. G., LAW, C. K., WANG, H., Combust. Flame, 119, no. 4, 1999, p. 375.

41. BRADLEY, D. MITCHESON, A., Combust. Flame, 26, 1976, p. 201. 42. BRINZEA, V., MITU, M., MOVILEANU, C., MUSUC, A., RAZUS, D., OANCEA, D., Rev. Chim. (Bucharest), 63, 2012, p. 289.

43. AGRAWAL, D., Combust. Flame, 42, 1981, p. 243.

44. GLASSMAN, I., YETTER, R., Combustion, $4^{\text {th }}$ Ed., Elsevier, 2008, Chapter 4.

45. LAW, C. K., Combustion Physics, Cambridge University Press, New York, 2006.

46. BRINZEA, V., MITU, M., RAZUS, D., OANCEA, D., Rev. Roumaine Chim., 55, 2010, p. 55.

47. BURKE, R., DEWAEL, F., VAN TIGGELEN, A., Combust. Flame, 7, 1963, p. 83.

48. KUMAR, K., MITTAL, G., SUNG, C. J., LAW, C. K., Combust. Flame, 153, no. 3, 2008, p. 343

49. GIURCAN, V., MITU, M., RAZUS, D., OANCEA, D., Rev. Chim. (Bucharest), 67, no. 6, 2016, p. 1084.

50. MITU, M., GIURCAN, V., RAZUS, D., OANCEA, D., Rev. Chim. (Bucharest), 69, no. 1, 2018, p. 196.

51. MITU, M., BRANDES, E., Rev. Chim. (Bucharest), 68, no. 5, 2017, p. 1035.

52. MITU, M., RAZUS, D., OANCEA, D., Rev. Chim. (Bucharest), 69, no. 4, 2018, p. 870.

53. MITU, M., BRANDES, E., Rev. Chim. (Bucharest), 69, no. 11, 2018, p. 2991.

Manuscript received: 29.08 .2018 